\title{
Dissecting the Rev-erb $\alpha$ Cistrome and the Mechanisms Controlling Circadian Transcription in Liver
}

\author{
Bin Fang and Mitchell A. Lazar \\ Division of Endocrinology, Diabetes, and Metabolism, Department of Medicine and Department \\ of Genetics, and The Institute for Diabetes, Obesity, and Metabolism, Perelman School of Medicine at the \\ University of Pennsylvania, Philadelphia, Pennsylvania 19104 \\ Correspondence: lazar@mail.med.upenn.edu
}

\begin{abstract}
Circadian clocks maintain whole-body metabolic homeostasis by coordinating rhythmic gene expression in multiple tissues. Core clock regulators sustain their own oscillation and confer expression rhythmicity on clock-controlled genes (CCGs). Our unbiased examination of enhancer RNA (eRNA) transcription around the clock in mouse liver identified functional enhancers of circadian genes driven by phase-specific transcription factors (TFs). Rev-erb $\alpha$ emerged as a primary driver of circadian enhancers, leading to oscillating gene expression in opposite phases through direct and indirect regulation. Among Rev-erb $\alpha$ target genes were core clock components and metabolic CCGs. Oscillation of clock genes was enforced by direct competition between Rev-erb $\alpha$ and $\operatorname{ROR} \alpha$ for binding to cognate motifs in the genome, whereas metabolic CCGs were governed by recruitment of the NCoR/HDAC3 complex to enhancers where Rev-erb $\alpha$ is tethered by tissue-specific TFs. The DNA sequence-mediated competition between Rev-erb $\alpha$ and ROR $\alpha$ ensures consistent clock control across all tissues. In contrast, the tethered binding mechanism is tissue-specific and thus allows Rev-erb $\alpha$ to dictate an epigenomic rhythm tailored to the specific need of that tissue. Therefore, discrete modes of recruitment allow Rev-erb $\alpha$ to link the clock to cell-specific functions, including metabolism.
\end{abstract}

Circadian rhythm evolved in living organisms through millions of years of adaptation to the near-24-h lightdark cycles on the earth. In mammals, a central clock residing in the suprachiasmatic nucleus (SCN) of the hypothalamus senses light as the primary zeitgeber and synchronizes clocks in peripheral tissues such as liver, heart, and adipose (Ko and Takahashi 2006; Mohawk et al. 2012). Peripheral clocks coordinate expression of clock-controlled genes (CCGs) in a feed-forward manner to anticipate physiological needs (Bass and Takahashi 2010; Huang et al. 2011). People with disrupted circadian rhythm, frequently observed in shift workers, are exposed to higher risk of metabolic derangements such as obesity, diabetes, and cardiovascular diseases (De Bacquer et al. 2009; Scheer et al. 2009; Pietroiusti et al. 2010).

Rev-erbo is a member of the nuclear receptor (NR) superfamily and a key component of the molecular clock in mammals (Mangelsdorf et al. 1995; Ko and Takahashi 2006). It binds DNA in a sequence-specific manner, recognizing RORE and RevDR2 motifs that are composed of classical NR half-site AGGTCA and an A/T-rich 5' flank (Harding and Lazar 1993). Lacking the classical NR transcriptional activation domain at its carboxyl terminus, Rev-erb $\alpha$ functions as a transcriptional repressor mainly through interacting with NR corepressor NCoR (Downes et al. 1996; Zamir et al. 1996). NCoR is in a tight complex with histone deacetylase 3 (HDAC3) (Guenther et al. 2001; Yoon et al. 2003), and Rev-erb $\alpha$ recruits both to the genome where it represses gene expression at least in part through histone deacetylation and chromatin condensation (Feng et al. 2011). RAR-related orphan receptors
(RORs) are transcriptional activators and recognize the same DNA targets as of Rev-erb $\alpha$ (Forman et al. 1994; Giguère et al. 1994). In addition to active recruitment of $\mathrm{NCoR} / \mathrm{HDAC} 3$, in vitro studies have suggested that Reverb $\alpha$ also represses gene expression by competing with RORs for binding to shared elements (Takeda et al. 2012).

Rev-erb $\alpha$ is a central component of the clock machinery, paired with the Bmall/Clock heterodimer in a feedback loop. Genetic ablation of Rev-erbo in mice shortened the period of locomotor activity in the constant darkness (Preitner et al. 2002), whereas disruption of both Rev-erb $\alpha$ and Rev-erb $\beta$, the paralog of Rev-erb $\alpha$, abrogated circadian gene expression in mouse embryonic fibroblasts and rendered wheel running behavior of adult mice arrhythmic (Bugge et al. 2012; Cho et al. 2012). Besides its function in driving the clock, Rev-erb $\alpha$ also maintains metabolic homeostasis in multiple tissues. In liver, Rev-erb $\alpha$ regulates cholesterol, bile acid, and lipid metabolism (Duez et al. 2008; Le Martelot et al. 2009), and Rev-erb $\alpha$ null mice developed hepatic steatosis (Feng et al. 2011). In brown adipose tissue (BAT), Reverb $\alpha$ controls thermogenesis by regulating expression of uncoupling protein 1 (UCP1), and mice genetically lacking Rev-erb $\alpha$ were resistant to the cold challenge (Gerhart-Hines et al. 2013). Rev-erb $\alpha$ was also suggested to regulate differentiation and mitochondria content in muscle cells (Downes et al. 1995; Woldt et al. 2013), insulin production and glucagon secretion in pancreas (Vieira et al. 2012), and inflammatory pathways in macrophages (Gibbs et al. 2012). Thus Rev-erb $\alpha$ is a critical transcriptional regulator for both metabolism and the clock. 
Several transcription activators and suppressors form the positive and negative limb of the molecular clock. They dictate the transcription machinery at opposite times of the day and convey transcriptional rhythmicity from the clock to the CCGs (Asher and Schibler 2011). In contrast to the well-studied clock structure, regulatory hierarchy of CCGs remains poorly understood. Recent studies using high-throughput DNA sequencing technologies unveiled a dynamic epigenomic landscape in circadian mouse liver, where vigorous chromatin remodeling was observed at tens of thousands genomic loci near thousands of circadian genes, shedding new light on the regulatory machinery of the circadian transcriptome (Koike et al. 2012; Menet et al. 2012). However, the exploration toward the precise regulatory hierarchy of the circadian transcriptome has just begun.

A recent study discovered short noncoding RNA transcripts produced by RNA polymerase II (Pol II) at enhancers, named eRNAs (Kim et al. 2010). It has been suggested that eRNA transcript bears regulatory functions in stabilizing the transcription machinery at gene promoters, either in cis or in trans (Li et al. 2013; Melo et al. 2013; Mousavi et al. 2013). Although it is uncertain to what extent eRNAs possess regulatory functions, several lines of evidence has pointed to the notion that eRNA transcription is coupled with that of its target genes, likely because of close proximity of enhancers and promoters brought together by chromatin looping (Hah et al. 2013; Li et al. 2013). Therefore, eRNA transcription is considered as a measurement of transcriptional activity that is conveyed from an enhancer to its target genes (Lam et al. 2014).

We set out to address questions as to how the uniquely phased molecular clock confers multiphasic oscillations on hepatic CCGs, and how tissue-specific metabolic functions are coupled to the clock. eRNA transcription in mouse liver was detected and quantified using global run-on sequencing (GRO-seq) (Core et al. 2008), and active enhancers were identified using an unbiased method. Analysis of dynamic eRNA transcription revealed phase-specific oscillators of circadian CCGs, among which Rev-erb $\alpha$ emerged as a predominate circadian regulator that governs nearly half of the circadian transcriptome in liver (Fang et al. 2014). Cistromic analysis in different mouse models revealed distinct mechanisms of Rev-erb $\alpha$ in regulating metabolism and the clock. Direct competition between Rev-erb $\alpha$ and ROR $\alpha$ at cognate binding sites drives oscillation of clock genes, whereas NCoR/HDAC3-mediated epigenomic remodeling, directed by Rev-erb $\alpha$ in a DNA-binding domain (DBD)-independent manner, orchestrates metabolic CCGs in liver (Zhang et al. 2015).

\section{Rev-erb $\alpha$ DRIVES RHYTHMIC GENE EXPRESSION AT MANY CIRCADIAN ENHANCERS}

GRO-seq was performed on mouse livers collected every $3 \mathrm{~h}$ throughout the 24-h light-dark cycle to obtain an unbiased view of active transcription at gene bodies as well as enhancers in liver. About $11 \%$ of the liver transcriptome was rhythmically transcribed, consistent with previous studies using other methods (Koike et al. 2012; Menet et al. 2012). We also identified thousands of eRNAs at sites that were highly enriched for epigenomic enhancer signatures such as H3K4me1, H3K27ac, and Pol II localization. Analysis of the dynamics of eRNA transcription revealed that $\sim 30 \%$ of enhancers were rhythmically transcribed. Remarkably, genes close to circadian enhancers showed rhythmic average transcription that was in phase with the eRNA expression, suggesting that rhythmic hepatic transcriptome is driven by circadian enhancers (Fang et al. 2014).

Although the core clock has one active and one repressive state, the phases of CCGs span the entire 24-h cycle. To investigate the molecular hierarchy dictating multiphasic gene expression in liver, we clustered circadian enhancers into eight phase groups at 3-h intervals. Motif analysis identified cell type-determining factors, such as HNF4, HNF6, and FOXA1, constitutively enriched in all phase groups. In addition, E-box, D-box, and Rev-DR2/ RORE motifs were predominantly enriched in circadian enhancers phasing in ZT6-9, ZT9-15, and ZT18-24, respectively. Concordantly, binding of BMAL1/CLOCK, $\mathrm{E} 4 \mathrm{BP} 4$, and Rev-erb $\alpha / \mathrm{ROR} \alpha$ were most prominent in the corresponding enhancer group, suggesting that circadian enhancers were separately controlled by primary phasespecific oscillators (Fang et al. 2014).

Although phases of circadian genes distributed evenly across the 24-h cycle, circadian enhancers were overrepresented in the dark phases. Indeed, $42 \%$ of enhancers reached their peak activities between ZT18 and ZT24, consistent with the previously reported global increase of H3K27 acetylation in the darkness (Koike et al. 2012). The majority of the genes phased at ZT18-24 were derepressed in Rev-erb $\alpha$ knockout (KO) mice at ZT10 when Rev-erb $\alpha$ is normally highly expressed and suppresses transcription at the maximum level, suggesting that circadian repression by Rev-erb $\alpha$ is the major determinant of their cyclic expression. Indeed, chromatin immunoprecipitation sequencing (ChIP-seq) analysis showed that binding of Rev-erb $\alpha$ was markedly enriched at in-phase circadian enhancers relative to other enhancers. In concordance, eRNA transcription at in-phase enhancers was markedly derepressed in the Rev-erb $\alpha \mathrm{KO}$ mice, whereas it was barely changed at out-of-phase and arrhythmic enhancers. Thus, Rev-erb $\alpha$ governs rhythmic expression of dark-phase genes at in-phase circadian enhancers. Interestingly, genome-wide analysis revealed that functional subset of Rev-erb $\alpha$ cistrome that controls circadian genes in liver accounts for $<10 \%$ of the total Rev-erb $\alpha$ binding sites near circadian genes. Thus Rev-erb $\alpha$ maintains liver circadian transcriptome using a small fraction of the cistrome, and analysis of eRNA transcription provides an excellent reflection of the "active" Rev-erb $\alpha$ cistrome.

Besides direct Rev-erb $\alpha$ target genes that were derepressed by Rev-erb $\alpha \mathrm{KO}$, a substantial set of genes were paradoxically down-regulated in the KO animals at ZT10, raising the possibility that they were regulated indirectly through another suppressor. Interestingly, these genes 
tended to be rhythmically expressed in phases ZT9-15, roughly antiphase to the direct targets of Rev-erb $\alpha$. Analysis of correlated eRNAs in the vicinity of those genes revealed overrepresented D-box motif. E4BP4, a transcription repressor and D-box family member, is normally highly expressed around ZT22 and silenced by Rev-erb $\alpha$ at ZT10. Binding of E4BP4 on the genome was markedly increased in the Rev-erb $\alpha \mathrm{KO}$ mice at ZT10, consistent with down-regulated expression of ZT9-15 genes. These results suggest that Rev-erb $\alpha$ indirectly controls circadian expression of ZT9-15 genes through E4BP4. Together, Rev-erb $\alpha$ directly and indirectly orchestrates nearly half of the circadian transcriptome in liver, accentuating its important role in coordinating circadian liver functions.

\section{Rev-erbs AND RORs COORDINATE THE CLOCK BY COMPETING AT COGNATE SITES}

Although RORs and Rev-erbs recognize the same motifs, they have opposing transcriptional activities and in vitro studies have suggested that the expression of a common target is determined by the outcome of the competition between the two factors (Liu et al. 2008; Takeda et al.
2012). Comparing gene expression changes in livers of ROR $\alpha / \gamma$ double knockout mice at ZT22 (when ROR expression is normally high) with gene expression in Reverb $\alpha$ knockout mice at ZT10 (when Rev-erb $\alpha$ expression is highest), we found several examples of common targets of Rev-erb $\alpha$ and RORs (Zhang et al. 2015). Among the common targets, clock genes such as Bmal1, Cry1, and Npas2 were overrepresented, consistent with the notion that RORs and Rev-erbs are core clock regulators (Ko and Takahashi 2006). ROR $\alpha$ occupancy increased at these genes in the absence of Rev-erb $\alpha$ and decreased when Rev-erb $\alpha$ was overexpressed in liver, demonstrating competition between Rev-erb $\alpha$ and $\operatorname{ROR} \alpha$ at these clock gene regulatory sites in vivo. At these sites, HDAC3 ablation only modestly increased gene expression at ZT10 and barely affected the rhythmicity of those genes, suggesting that direct competition between Rev-erb $\alpha$ and $\operatorname{ROR} \alpha$ is the primary force of clock oscillation in liver (Zhang et al. 2015).

The molecular clock operates in a variety of tissues, suggesting that competition between Rev-erb $\alpha$ and RORs near clock genes might be consistent across tissues. Indeed, common binding sites of Rev-erb $\alpha$ among multiple tissues are evolutionarily conserved (Fig. 1A) and highly
A

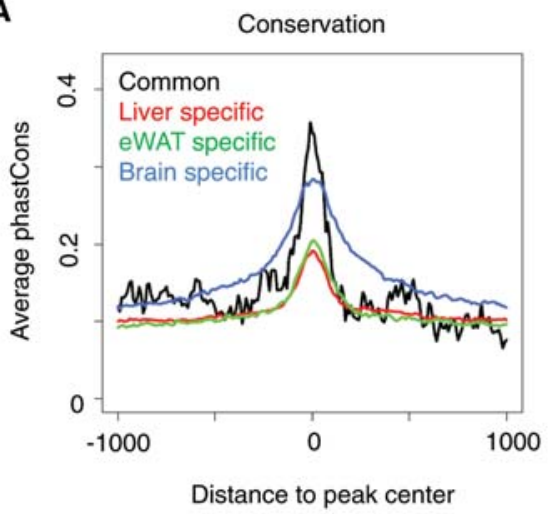

C

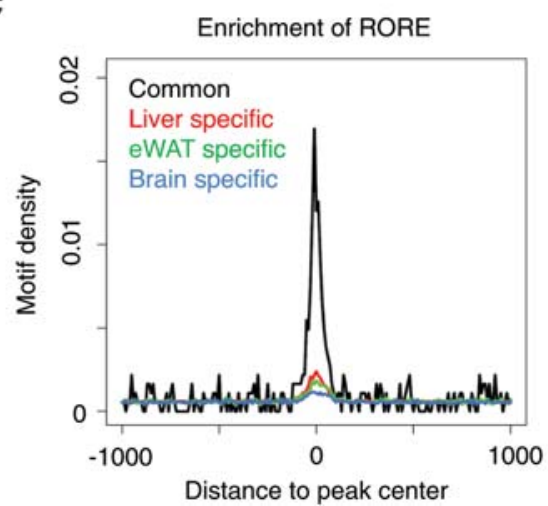

B

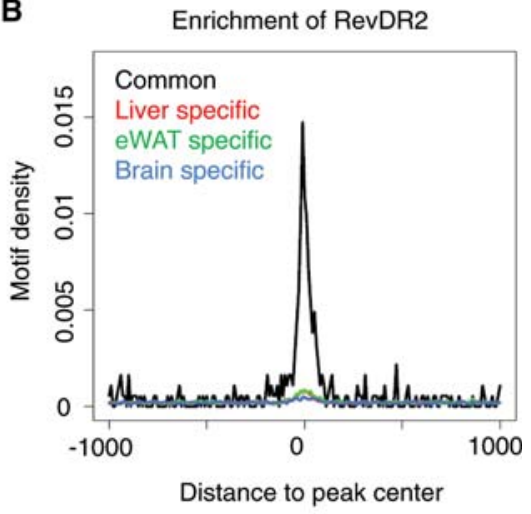

D

Rev-erb $\alpha$ Cistrome in three tissues

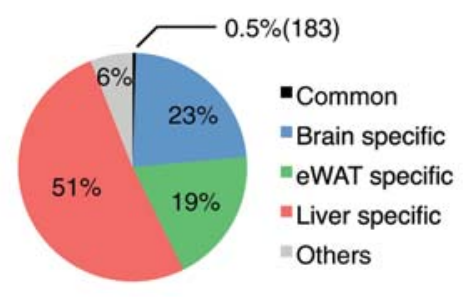

Genes near common binding sites Bmal1, Cry1, Npas2, Nr1d1, E4bp4

Figure 1. Tissue-specific Rev-erb $\alpha$ cistromes. $(A)$ Average phastCons score for $2-\mathrm{kb}$ windows centered at common and tissue-specific Rev-erb $\alpha$ binding sites in liver, brain, and epididymal white adipose tissue (eWAT). (B) Density of RevDR2 motif (average motifs per peak per bin) in 2-kb windows centered at common and tissue-specific Rev-erb $\alpha$ binding sites. (C) Density of RORE motif in 2-kb windows of Rev-erb $\alpha$ binding sites. $(D)$ Pie chart represents the total Rev-erb $\alpha$ cistrome identified in three tissues. Sizes of tissuespecific cistrome and shared cistrome across tissues are shown. Clock genes within $50 \mathrm{~kb}$ of 183 common Rev-erb $\alpha$ binding sites (black) are listed on the bottom. 
enriched for the RevDR2 and RORE motifs where Rev-erb $\alpha$ and ROR $\alpha$ compete (Fig. 1B,C). Furthermore, clock genes such as Bmal1, Cry1, and Npas2 were all bound by those common Rev-erb $\alpha$ sites (Fig. 1D), suggesting that direct competition between Rev-erb $\alpha$ and $\operatorname{ROR} \alpha$ is a universal mechanism of clock oscillation in all tissues.

\section{Rev-erb $\alpha$ REGULATES LIPID METABOLIC GENES THROUGH ACTIVE REPRESSION AT TETHERED SITES}

Although the binding sites at clock genes were common to the Rev-erb $\alpha$ cistromes in liver, WAT, and brain, the vast majority of binding sites were tissue-specific (Fig. 1D). Moreover, in the liver, the vast majority of Reverb $\alpha$ target genes, as detected by derepressed expression in Rev-erb $\alpha \mathrm{KO}$ mice, were unaffected by deletion of RORs, suggesting that competition between RORs and Rev-erb $\alpha$ plays a highly restricted role that does not explain the function of Rev-erb $\alpha$ at the majority of CCGs that it regulates.

RevDR2 and RORE motifs were less enriched in tissue-specific sites than at clock genes (Fig. 1B,C), suggesting that other TFs may be involved in the recruitment of Rev-erb $\alpha$ to the genome. In agreement, although RevDR2 and RORE were the most differentially enriched motifs in ZT18-24 eRNAs (Fang et al. 2014), more than half of the active Rev-erb $\alpha$ cistrome producing ZT18-24 eRNAs lacked the RevDR2 and RORE motifs but contained constitutive motifs of circadian enhancers in liver (Fig. 2A). RevDR2 and RORE motifs were enriched in direct Rev-erb $\alpha$ binding sites that diminished in the absence of the DBD (Zhang et al. 2015). The enrichment of constitutive motifs in Rev-erb $\alpha$ sites that were unaffected by the DBD deletion suggests several candidate factors that might recruit Rev-erb $\alpha$ to the genome (Fig. 2B).
Base pair resolution of the liver Rev-erbo cistrome using ChIP-exonuclease followed by high-throughput sequencing (ChIP-exo) (Rhee and Pugh 2011) revealed many Rev-erb $\alpha$ binding sites centered at the binding motif of HNF6, a liver determination factor. Rev-erb $\alpha$ functioned as a repressor of rhythmic eRNAs at these sites, which were also bound by Rev-erb $\alpha$ corepressor HDAC3 (Zhang et al. 2015). Moreover, HNF6 and Rev-erb $\alpha$ colocalized at these sites, and Rev-erb $\alpha$ binding was abolished or severely attenuated by genetic disruption of the HNF6 motif. Reciprocally, the DBD of Rev-erb $\alpha$ was not required for binding to the majority of these sites (Zhang et al. 2015). Thus, HNF6 mediated DBD-independent binding of Rev-erb $\alpha$ at liverspecific bind sites.

Genes near these binding sites were enriched in hepatic metabolic functions, including lipid metabolism, suggesting that tethered binding may allow Rev-erb $\alpha$ to exert regulatory control on tissue-specific, metabolic genes. Indeed, many of the Rev-erb $\alpha$ target genes enriched in hepatic metabolic functions were not derepressed by the loss of the DBD. Further, whereas the absence of Rev-erb $\alpha$ leads to fatty liver in $\mathrm{C} 57 \mathrm{Bl} / 6$ mice (Feng et al. 2011; Bugge et al. 2012), hepatic triglyceride levels were not significantly altered by the loss of the DBD (Zhang et al. 2015). In contrast, mice lacking the Reverb $\alpha$ DBD exhibited altered circadian locomotor behavior (Cho et al. 2012), consistent with the critical role of the DBD in regulating clock functions. Thus the clock and metabolic functions are regulated by Rev-erb $\alpha$ through discrete, DBD-dependent and DBD-independent mechanisms, at the times of day when Rev-erbo is expressed (Fig. 3).

\section{CONCLUSION}

The central clock oscillates in near-24-h cycles and coordinates rhythm of peripheral clock in a variety of tissues. Synchronized cells in all tissues together con-
A

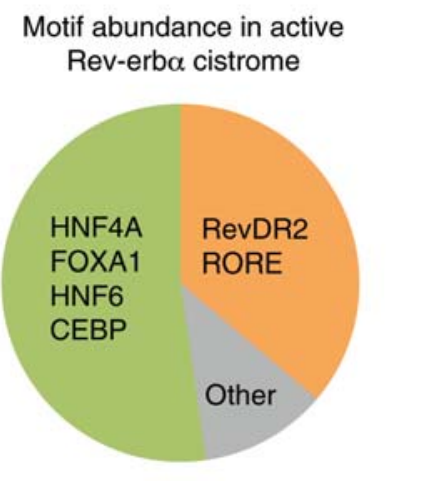

B

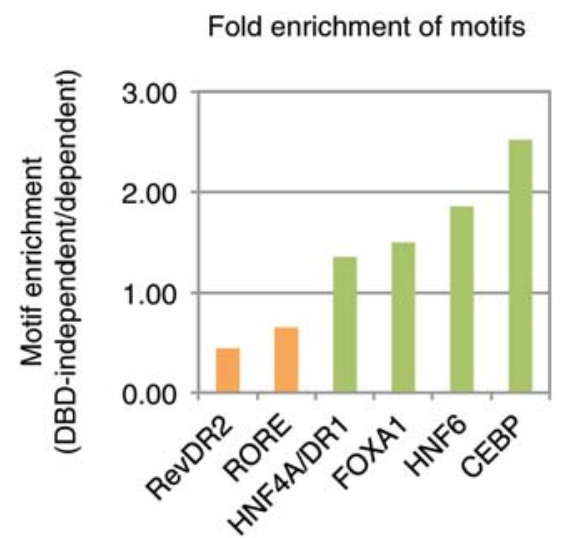

Figure 2. Motif composition in the active Rev-erb $\alpha$ cistrome. (A) Pie chart represents 1448 Rev-erb $\alpha$ binding sites producing circadian eRNAs in phase ZT18-24. RevDR2 and RORE motif were found in 36\% of the sites (orange), whereas 53\% of the peaks (green) lacked RevDR2 or RORE motif but contained constitutive motifs of circadian enhancers. Eleven percent of the peaks (gray) contained other motifs. (B) Fold enrichment of RevDR2, RORE, and constitutive motifs in DNA-binding domain (DBD)-independent versus DBDdependent binding sites. 
Direct binding at clock genes

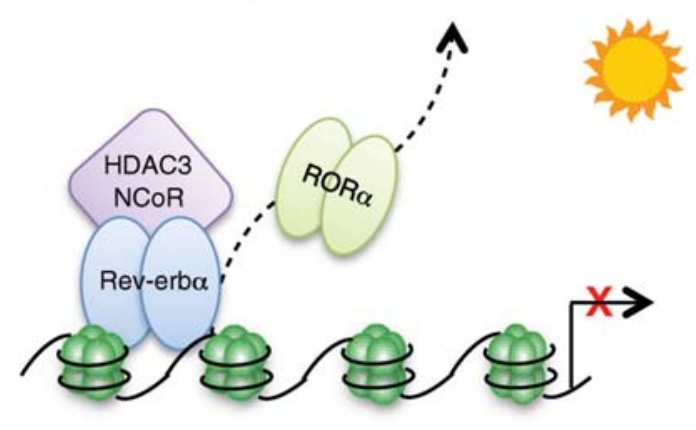

Repression requires DNA binding

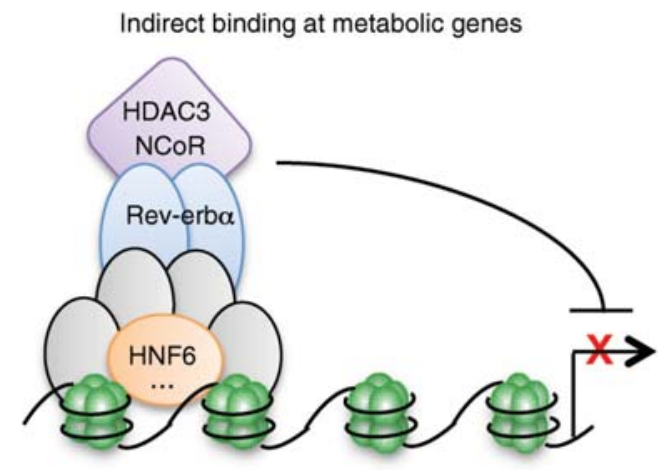

Repression requires HDAC3

Figure 3. Model depicting distinct mechanisms of Rev-erb $\alpha$ regulating clock and metabolic genes in liver. Clock genes are repressed in the light cycle (in mice) owing to evicted ROR $\alpha$ by direct competition of Rev-erb $\alpha$ (left panel). Metabolic genes are repressed in the light cycle by Rev-erb $\alpha / \mathrm{NCoR} / \mathrm{HDAC} 3$ complexes recruited to the genome by tissue-specific factors such as, but not limited to, HNF6. This process is independent from the DNA-binding domain of Rev-erbo (right panel).

vey physiological adjustments to anticipate upcoming environmental and metabolic changes. Although the interlocked loop structures of the core clock have been well appreciated, connections between the core clock and tissue-specific CCGs remain poorly understood. Analysis of rhythmic transcription has elucidated a landscape of active enhancers that govern circadian gene expression in mouse liver. Rev-erb $\alpha$ has emerged as a predominant direct regulator of dark phase circadian genes, as well as an indirect regulator of circadian genes in other phases via its repression of E4BP4.

Rev-erb $\alpha$ maintains whole-body metabolic homeostasis by regulating distinct metabolic pathways in multiple tissues (Everett and Lazar 2014). The tissue-specific cistrome of Rev-erb $\alpha$ is likely related to these tissue-specific functions. For example, Rev-erb $\alpha$ binds and represses the uncoupling protein 1 gene in brown adipose tissue (Gerhart-Hines et al. 2013), whereas both of these functions are absent in the liver. Given the notion that TFs colocalize at hot spots throughout the genome (Boergesen et al. 2012; Siersbaek et al. 2014), tethering might be a general way for TFs to be recruited in a tissue-specific manner.

Our study demonstrated that Rev-erb $\alpha$ competes with $\mathrm{ROR} \alpha$ for binding conserved cognate sites near clock genes, exerting consistent clock oscillation across multiple tissues (Fig. 2). In contrast, metabolic CCGs in liver are dictated by NCoR/HDAC3-mediated rhythmic epigenomic remodeling, which may confer on Rev-erb $\alpha$ the ability to adapt environmental changes, perhaps through endogenous ligand heme (Raghuram et al. 2007; Yin et al. 2007). Notably, binding of Rev-erb $\alpha$ at hepatic CCGs was independent from its DBD; thus, synthetic ligand altering interactions between Rev-erb and NCoR/HDAC3 may modulate hepatic metabolism without affecting the circadian clock. Although the molecular clock is self-sustained in the absence of external cues, metabolism is dynamic and sensitive to changes in nutrient and energy states. Thus, these dual modes of Reverb $\alpha$ action facilitate its role as a bridging factor of the two systems.

\section{ACKNOWLEDGMENTS}

We thank our colleagues who participated in the work summarized here from the Lazar laboratory, particularly Anne Bugge, Logan Everett, Dan Feng, Jennifer Jager, and Yuxiang Zhang. This work was supported by National Institutes of Health grant R01 DK45586 (M.A.L.) and the JPB Foundation.

\section{REFERENCES}

Asher G, Schibler U. 2011. Crosstalk between components of circadian and metabolic cycles in mammals. Cell Metab 13: 125-137.

Bass J, Takahashi JS. 2010. Circadian integration of metabolism and energetics. Science 330: 1349-1354.

Boergesen M, Pedersen TA, Gross B, van Heeringen SJ, Hagenbeek D, Bindesbøll C, Caron S, Lalloyer F, Steffensen KR, Nebb HI, et al. 2012. Genome-wide profiling of liver X receptor, retinoid $\mathrm{X}$ receptor, and peroxisome proliferator-activated receptor $\alpha$ in mouse liver reveals extensive sharing of binding sites. Mol Cell Biol 32: 852-867.

Bugge A, Feng D, Everett LJ, Briggs ER, Mullican SE, Wang F, Jager J, Lazar MA. 2012. Rev-erb $\alpha$ and Rev-erb $\beta$ coordinately protect the circadian clock and normal metabolic function. Genes Dev 26: 657-667.

Cho H, Zhao X, Hatori M, Yu RT, Barish GD, Lam MT, Chong LW, DiTacchio L, Atkins AR, Glass CK, et al. 2012. Regulation of circadian behaviour and metabolism by REV-ERB- $\alpha$ and REV-ERB- $\beta$. Nature 485: $123-127$.

Core LJ, Waterfall JJ, Lis JT. 2008. Nascent RNA sequencing reveals widespread pausing and divergent initiation at human promoters. Science 322: 1845-1848.

De Bacquer D, Van Risseghem M, Clays E, Kittel F, De Backer G, Braeckman L. 2009. Rotating shift work and the metabolic syndrome: A prospective study. Int J Epidemiol 38: $848-854$

Downes M, Carozzi AJ, Muscat GE. 1995. Constitutive expression of the orphan receptor, Rev-erbA $\alpha$, inhibits muscle differentiation and abrogates the expression of the myoD gene family. Mol Endocrinol 9: 1666-1678.

Downes M, Burke LJ, Bailey PJ, Muscat GE. 1996. Two receptor interaction domains in the corepressor, N-CoR/RIP13, are required for an efficient interaction with Rev-erbA $\alpha$ and RVR: Physical association is dependent on the E region of the orphan receptors. Nucleic Acids Res 24: 4379-4386. 
Duez H, van der Veen JN, Duhem C, Pourcet B, Touvier T, Fontaine C, Derudas B, Bauge E, Havinga R, Bloks VW, et al. 2008. Regulation of bile acid synthesis by the nuclear receptor Rev-erb $\alpha$. Gastroenterology 135: 689-698.

Everett LJ, Lazar MA. 2014. Nuclear receptor Rev-erb $\alpha$ : Up, down, and all around. Trends Endocrinol Metab 25: 586592.

Fang B, Everett LJ, Jager J, Briggs E, Armour SM, Feng D, Roy A, Gerhart-Hines Z, Sun Z, Lazar MA. 2014. Circadian enhancers coordinate multiple phases of rhythmic gene transcription in vivo. Cell 159: $1140-1152$.

Feng D, Liu T, Sun Z, Bugge A, Mullican SE, Alenghat T, Liu XS, Lazar MA. 2011. A circadian rhythm orchestrated by histone deacetylase 3 controls hepatic lipid metabolism. Science 331: 1315-1319.

Forman BM, Chen J, Blumberg B, Kliewer SA, Henshaw R, Ong ES, Evans RM. 1994. Cross-talk among ROR $\alpha 1$ and the Rev-erb family of orphan nuclear receptors. Mol Endocrinol 8: $1253-1261$.

Gerhart-Hines Z, Feng D, Emmett MJ, Everett LJ, Loro E, Briggs ER, Bugge A, Hou C, Ferrara C, Seale P, et al. 2013. The nuclear receptor Rev-erb $\alpha$ controls circadian thermogenic plasticity. Nature 503: 410-413.

Gibbs JE, Blaikley J, Beesley S, Matthews L, Simpson KD, Boyce SH, Farrow SN, Else KJ, Singh D, Ray DW, et al. 2012. The nuclear receptor REV-ERB $\alpha$ mediates circadian regulation of innate immunity through selective regulation of inflammatory cytokines. Proc Natl Acad Sci 109: $582-$ 587.

Giguère V, Tini M, Flock G, Ong E, Evans RM, Otulakowski G. 1994. Isoform-specific amino-terminal domains dictate DNA-binding properties of ROR $\alpha$, a novel family of orphan hormone nuclear receptors. Genes Dev 8: 538-553.

Guenther MG, Barak O, Lazar MA. 2001. The SMRT and NCoR corepressors are activating cofactors for histone deacetylase 3. Mol Cell Biol 21: 6091-6101.

Hah N, Murakami S, Nagari A, Danko CG, Kraus WL. 2013. Enhancer transcripts mark active estrogen receptor binding sites. Genome Res 23: 1210-1223.

Harding HP, Lazar MA. 1993. The orphan receptor Rev-ErbA $\alpha$ activates transcription via a novel response element. Mol Cell Biol 13: 3113-3121.

Huang W, Ramsey KM, Marcheva B, Bass J. 2011. Circadian rhythms, sleep, and metabolism. J Clin Invest 121: $2133-$ 2141.

Kim TK, Hemberg M, Gray JM, Costa AM, Bear DM, Wu J, Harmin DA, Laptewicz M, Barbara-Haley K, Kuersten S, et al. 2010. Widespread transcription at neuronal activity-regulated enhancers. Nature 465: 182-187.

Ko CH, Takahashi JS. 2006. Molecular components of the mammalian circadian clock. Hum Mol Genet 15(Spec No 2): R271-R277.

Koike N, Yoo SH, Huang HC, Kumar V, Lee C, Kim TK, Takahashi JS. 2012. Transcriptional architecture and chromatin landscape of the core circadian clock in mammals. Science 338: $349-354$.

Lam MT, Li W, Rosenfeld MG, Glass CK. 2014. Enhancer RNAs and regulated transcriptional programs. Trends Biochem Sci 39: 170-182.

Le Martelot G, Claudel T, Gatfield D, Schaad O, Kornmann B, Lo Sasso G, Moschetta A, Schibler U. 2009. REV-ERB $\alpha$ participates in circadian SREBP signaling and bile acid homeostasis. PLoS Biol 7: e1000181.

Li W, Notani D, Ma Q, Tanasa B, Nunez E, Chen AY, Merkurjev D, Zhang J, Ohgi K, Song X, et al. 2013. Functional roles of enhancer RNAs for oestrogen-dependent transcriptional activation. Nature 498: 516-520.

Liu AC, Tran HG, Zhang EE, Priest AA, Welsh DK, Kay SA. 2008. Redundant function of REV-ERB $\alpha$ and $\beta$ and nonessential role for Bmall cycling in transcriptional regulation of intracellular circadian rhythms. PLoS Genet 4: e1000023.
Mangelsdorf DJ, Thummel C, Beato M, Herrlich P, Schutz G, Umesono K, Blumberg B, Kastner P, Mark M, Chambon P, et al. 1995. The nuclear receptor superfamily: The second decade. Cell 83: 835-839.

Melo CA, Drost J, Wijchers PJ, van de Werken H, de Wit E, Oude Vrielink JA, Elkon R, Melo SA, Léveillé N, Kalluri R, et al. 2013. eRNAs are required for p53-dependent enhancer activity and gene transcription. Mol Cell 49: 524-535.

Menet JS, Rodriguez J, Abruzzi KC, Rosbash M. 2012. NascentSeq reveals novel features of mouse circadian transcriptional regulation. Elife 1: e00011.

Mohawk JA, Green CB, Takahashi JS. 2012. Central and peripheral circadian clocks in mammals. Annu Rev Neurosci 35: 445-462.

Mousavi K, Zare H, Dell'orso S, Grontved L, Gutierrez-Cruz G, Derfoul A, Hager GL, Sartorelli V. 2013. eRNAs promote transcription by establishing chromatin accessibility at defined genomic loci. Mol Cell 51: 606-617.

Pietroiusti A, Neri A, Somma G, Coppeta L, Iavicoli I, Bergamaschi A, Magrini A. 2010. Incidence of metabolic syndrome among night-shift healthcare workers. Occup Environ Med 67: $54-57$.

Preitner N, Damiola F, Lopez-Molina L, Zakany J, Duboule D, Albrecht U, Schibler U. 2002. The orphan nuclear receptor REV-ERB $\alpha$ controls circadian transcription within the positive limb of the mammalian circadian oscillator. Cell 110: $251-260$.

Raghuram S, Stayrook KR, Huang P, Rogers PM, Nosie AK, McClure DB, Burris LL, Khorasanizadeh S, Burris TP, Rastinejad F. 2007. Identification of heme as the ligand for the orphan nuclear receptors REV-ERB $\alpha$ and REV-ERB $\beta$. Nat Struct Mol Biol 14: 1207-1213.

Rhee HS, Pugh BF. 2011. Comprehensive genome-wide proteinDNA interactions detected at single-nucleotide resolution. Cell 147: 1408-1419.

Scheer FA, Hilton MF, Mantzoros CS, Shea SA. 2009. Adverse metabolic and cardiovascular consequences of circadian misalignment. Proc Natl Acad Sci 106: 4453-4458.

Siersbaek R, Baek S, Rabiee A, Nielsen R, Traynor S, Clark N, Sandelin A, Jensen ON, Sung MH, Hager GL, et al. 2014. Molecular architecture of transcription factor hotspots in early adipogenesis. Cell Rep 7: 1434-1442.

Takeda Y, Jothi R, Birault V, Jetten AM. 2012. ROR $\gamma$ directly regulates the circadian expression of clock genes and downstream targets in vivo. Nucleic Acids Res 40: 8519-8535.

Vieira E, Marroquí L, Batista TM, Caballero-Garrido E, Carneiro EM, Boschero AC, Nadal A, Quesada I. 2012. The clock gene Rev-erb $\alpha$ regulates pancreatic $\beta$-cell function: Modulation by leptin and high-fat diet. Endocrinology 153: $592-601$.

Woldt E, Sebti Y, Solt LA, Duhem C, Lancel S, Eeckhoute J, Hesselink MK, Paquet C, Delhaye S, Shin Y, et al. 2013. Reverb- $\alpha$ modulates skeletal muscle oxidative capacity by regulating mitochondrial biogenesis and autophagy. Nat Med 19: 1039-1046.

Yin L, Wu N, Curtin JC, Qatanani M, Szwergold NR, Reid RA, Waitt GM, Parks DJ, Pearce KH, Wisely GB, et al. 2007. Reverb $\alpha$, a heme sensor that coordinates metabolic and circadian pathways. Science 318: 1786-1789.

Yoon HG, Chan DW, Huang ZQ, Li J, Fondell JD, Qin J, Wong J. 2003. Purification and functional characterization of the human N-CoR complex: The roles of HDAC3, TBL1 and TBLR1. EMBO J 22: 1336-1346.

Zamir I, Harding HP, Atkins GB, Hörlein A, Glass CK, Rosenfeld MG, Lazar MA. 1996. A nuclear hormone receptor corepressor mediates transcriptional silencing by receptors with distinct repression domains. Mol Cell Biol 16: 5458-5465.

Zhang Y, Fang B, Emmett MJ, Damle M, Sun Z, Feng D, Armour SM, Remsberg JR, Jager J, Soccio RE, et al. 2015. Discrete functions of nuclear receptor Rev-erb $\alpha$ couple metabolism to the clock. Science 348: 1488-1492. 


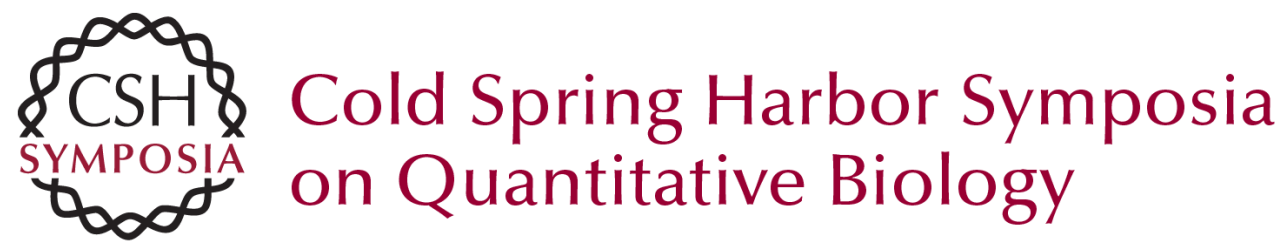

\section{Dissecting the Rev-erb $\alpha$ Cistrome and the Mechanisms Controlling Circadian Transcription in Liver}

Bin Fang and Mitchell A. Lazar

Cold Spring Harb Symp Quant Biol 2015 80: 233-238 originally published online September 14, 2015

Access the most recent version at doi:10.1101/sqb.2015.80.027508

References This article cites 46 articles, 17 of which can be accessed free at: http://symposium.cshlp.org/content/80/233.full.html\#ref-list-1

\section{License}

Email Alerting Receive free email alerts when new articles cite this article - sign up in Service the box at the top right corner of the article or click here. 